\title{
Kernos
}

Revue internationale et pluridisciplinaire de religion grecque antique

5 | 1992

Varia

\section{In memoriam Charles Delvoye}

\section{Guy Donnay}

\section{OpenEdition}

Journals

\section{Édition électronique}

URL : http://journals.openedition.org/kernos/1043

DOI : 10.4000/kernos.1043

ISSN : 2034-7871

\section{Éditeur}

Centre international d'étude de la religion grecque antique

\section{Édition imprimée}

Date de publication : 1 janvier 1992

ISSN : 0776-3824

\section{Référence électronique}

Guy Donnay, «In memoriam Charles Delvoye », Kernos [En ligne], 5 | 1992, mis en ligne le 19 avril 2011, consulté le 21 avril 2019. URL : http://journals.openedition.org/kernos/1043 


\section{IN MEMORIAM CHARLES DELVOYE}

Deux ans après le décès de son président d'honneur, Georges E. Mylonas, le C.E.R.G.A. est à nouveau en deuil: son fondateur d'honneur, Charles Delvoye, nous a quittés brutalement le 9 décembre dernier; il avait 74 ans. Ses amis et ses anciens élèves conservent de lui le souvenir d'un homme d'une grande exigence intellectuelle, mais aussi d'une grande ouverture d'esprit et d'une grande bonté. Son engagement sincère à gauche ne l'empêchait nullement d'entretenir des relations amicales avec des hommes et des femmes de toutes opinions. Naturellement doux et bienveillant, il était néanmoins capable d'emportements violents pour dénoncer les atteintes aux principes de liberté, de tolérance et de respect des autres auxquels il était farouchement attaché. Car ce pur produit de l'université, qui a mené une carrière académique exemplaire - chercheur au Fonds national belge de la recherche scientifique de 1942 à 1952, puis professeur à l'Université de Bruxelles jusqu'à sa mise à la retraite en 1987 -, n'était pas seulement un savant de cabinet: sa conduite pendant la seconde guerre mondiale lui valut la médaille de la Résistance.

Après un premier voyage en Grèce en 1938, son passage à l'École française d'Athènes de 1947 à 1949 lui fait découvrir, outre l'antique Hellade, objet de ses études, un pays attachant alors plongé en pleine guerre civile, et le convainc de l'impossibilité de comprendre la première sans connaître - et aimer - le second. Dès lors, il ne cessera de vibrer à chacun des événements qui marqueront la vie de la Grèce contemporaine, où il a noué de solides amitiés. Peu après le putsch militaire d'avril 1967, je me rappelle l'avoir ramené à Bruxelles un soir à tombeau ouvert, à l'issue d'une conférence qu'il avait donnée en province, pour lui permettre d'assister à un meeting improvisé de Mikis Théodorakis. Le hasard voulut qu'il se trouvât en vacances à Famagouste en juillet 1974, lors de l'invasion turque; s'il se réjouit du retour de la démocratie à Athènes, le prix payé par les Chypriotes grecs l'affecta douloureusement.

Le titre. de l'ouvrage collectif La civilisation grecque de l'Antiquité à nos jours, dont il dirigea la publication avec son camarade "athénien" Georges Roux, résume bien sa vision d'un hellénisme qui ne saurait se limiter aux siècles de Solon et de Périclès, ni même à ceux 
d'Alexandre et des Diadoques ${ }^{1}$. Si ses premiers articles traitent, comme sa dissertation doctorale soutenue en 1946, de la Grèce préhellénique, la parution en 1967 de son manuel d'art byzantin - qui sera traduit en grec et en roumain - le consacre comme un des maîtres de cette discipline, ce qui ne l'empêche pas d'écrire à l'occasion sur la nouvelle présentation des frontons d'Égine à la Glyptothèque de Munich ou le développement des arts plastiques à Athènes pendant la guerre du Péloponnèse ${ }^{2}$. Sa curiosité insatiable d'humaniste l'entraîne aussi en dehors du monde grec. Titulaire du cours d'histoire de la sculpture, il analyse avec autant de finesse le programme décoratif du Parthénon et celui de château de Versailles, les guerriers de Riace et les portraits de Houdon.

Pas plus qu'il n'accepte de réduire la Grèce à une période, si prestigieuse soit-elle, il n'accepte de réduire l'histoire de l'art à l'étude de l'évolution de formes désincarnées. Séduit par les thèses d'inspiration maxiste de Ranuccio Bianchi-Bandinelli sur l'historicité de l'art antique $^{3}$, il ne conçoit pas que ce dernier - pas plus que les arts d'autres époques ou d'autres lieux - puisse être considéré comme une simple création intellectuelle. Pour lui, l'œuvre d'art n'est pas seulement un objet de contemplation et de plaisir esthétique: elle constitue d'abord un témoignage sur les hommes par qui et pour qui elle a été faite. Produit d'une société donnée, son approche est indissociable de celle des autres témoignages à travers lesquels nous pouvons tenter de connaître cette société.

La double formation de philologue et d'historien de l'art de Charles Delvoye lui ouvrait un accès direct aux divers types de sources grâce auxquelles il lui était loisible d'évoquer ces autres témoignages et de proposer une reconstitution personnelle du contexte politique, littéraire, philosophique des œuvres qu'il étudiait. Ce faisant, il ne pouvait manquer d'aborder à mainte reprise le domaine de la religion: les cultes préhelléniques et classiques, mais aussi et surtout le christianisme byzantin que, athée convaincu, il s'attachait à comprendre avec une profonde sympathie - au sens étymologique du terme. Aussi à l'aise avec les textes qu'avec les monuments, combien de problèmes d'architecture ou d'iconographie ne réussit-il pas à élucider à la lumière des controverses théologiques contemporaines, dans le dédale desquelles il se mouvait avec une virtuosité stupéfiante?

1 Bruxelles, La Renaissance du Livre, 1967.

2 On trouvera la liste des ses publications dans Rayonnement grec. Hommages à Charles Delvoye (Éditions de l'Université de Bruxelles, 1982), p. 5-14.

3 Storicità dell'arte antica, $2^{\mathrm{e}}$ éd. (Florence, Electa, 1950). 
Faut-il s'étonner, dès lors, qu'il figure parmi les initiateurs, en 1965, de l'Institut d'histoire du christianisme de l'U.L.B., devenu aujourd'hui l'Institut d'étude des religions et de la laïcité ? Les mêmes motivations allaient le pousser à participer, quelque vingt ans plus tard, à la création du C.E.R.G.A. L'amitié et la considération dont il jouissait tant en Grèce qu'en Belgique lui valurent le titre, qu'il n'avait pas sollicité, de fondateur d'honneur de notre Centre. Il le portera à jamais dans nos cœurs.

Guy DONNAY

Professeur à l'Université de Bruxelles

Premier vice-président du C.E.R.G.A. 